\title{
Margaret McCartney: Can we now talk openly about the risks of screening?
}

\author{
Margaret McCartney general practitioner
}

Glasgow

The computer error that caused hundreds of thousands of women not to be invited for breast screening as intended has shone a new spotlight on cancer screening.

Jeremy Hunt has said that, because of this administrative error, "there may be between 135 and 270 women who have had their lives shortened as a result." ${ }^{\prime 1}$ find it totally bizarre that the health secretary should make such a statement when we don't have evidence that breast screening reduces all cause mortality. ${ }^{2}$

It's quite right to apologise when things go wrong, but Hunt's statement didn't make clear the difference between breast cancer specific mortality and all cause mortality. This doesn't help women who haven't been invited for screening or who are currently considering an invitation. Are we so invested in keeping up the status of breast screening as a sacred cow that the health secretary can't talk about its limitations?

It's a rare thing for me to criticise the Department of Health for scaremongering over the effect of its mistakes, but there we have it. And let's not forget that, by its own modelling, as many as 810 women will have avoided the risks of overdiagnosis and overtreatment.

It's a rare thing for me to criticise the Department of Health for scaremongering over the effect of its mistakes

The women over 70 who missed their invitation are part of this story because they should have received their invitations as part of the Age Extension Trial. What do we know about the trial? It's enormous: the target was changed in 2016 from "at least" three million women to six million. ${ }^{3}$

It's also controversial. The original study protocol says that section 251 approval for "including women in the trial without their consent" has been granted. It adds, "With respect to consent for screening, the standard procedures of the NHS Breast Screening Programme apply, whereby attending screening is taken as implied consent."

The ethics of this are dubious. For several years, the information leaflet women received about the trial did not explicitly state that they were being invited for screening as part of a trial. ${ }^{5}$ Yet a report by Michael Marmot and colleagues on the benefits and harms of breast cancer screening concluded, "The impact of breast screening outside the ages of 50-69 years is very uncertain."

The initial hypothesis of the Age Extension Trial stated, "The age extension will proceed regardless of whether this study goes ahead or not, and therefore regardless of whether the phasing-in is randomised or not." ${ }^{3}$ This would be a travesty of ethical practice, and the hypothesis was amended in 2015 to say that "future decisions about extending routine NHS breast cancer screening outside the age range 50-70 years should await the emergence of reliable evidence as to its effects." Indeed; but surely the Data Monitoring Committee should have been given the information generated by the trial—and been able to detect the missing invitations over the past nine years.

The missed invitations for breast screening mean that there is now a large dataset that may be able to answer questions on the effectiveness of breast screening in the later part of the programme. Public health doctors, clinical staff, and civil servants in screening should be able to start talking openly about how the effects of non-invitation may not make much difference overall.

Competing interests: See www.bmj.com/about-bmj/freelance-contributors/margaretmccartney.

Provenance and peer review: Commissioned; not externally peer reviewed.

House of Commons Hansard. Statement on breast cancer screening. 2 May 2018. https: /hansard.parliament.uk/commons/2018-05-02/debates/BE9DB48A-C9FF-401B-AC54//hansard.parliament.uk/commons/2018-05-02

2 Gøtzsche PC, Jørgensen KJ. Screening for breast cancer with mammography. Cochrane Database Syst Rev 2013;6:CD001877. 10.1002/14651858.CD001877.pub5. http:// cochranelibrary-wiley.com/doi/10.1002/14651858.CD001877.pub5/abstract. 23737396

3 ISRCTN Registry. Nationwide cluster-randomised trial of extending the NHS breast screening age range in England. www.isrctn.com/ISRCTN33292440.

4 University of Oxford. AgeX trial protocol. 2016. http://www.agex.uk/file_download/13/ AgeX+protocol.pdf.

5 HealthWatch. Concerns over age extension trial. 17 Jan 2015. https://www.healthwatchuk.org/news/49-concerns-over-age-extension-trial-of-mammography-screening-part-3. html.

6 Marmot MG, Altman DG, Cameron DA, Dewar JA, Thompson SG, Wilcox MIndependent UK Panel on Breast Cancer Screening. The benefits and harms of breast cancer screening: a report jointly commissioned by Cancer Research UK and the Department of Health 
(England). Br J Cancer 2013;108:2205-40. https://www.ncbi.nlm.nih.gov/pmc/articles/ PMC3693450/10.1038/bjc.2013.177 23744281
Published by the BMJ Publishing Group Limited. For permission to use (where not already granted under a licence) please go to http://group.bmj.com/group/rights-licensing/ permissions 